\title{
Archaeal and bacterial community composition of a pristine coastal aquifer in Doñana National Park, Spain
}

\author{
Ana Isabel López-Archilla ${ }^{1, *}$, David Moreira ${ }^{2}$, Sergio Velasco ${ }^{1}$, \\ Purificación López-García ${ }^{2}$
}

${ }^{1}$ Departamento de Ecología, Facultad de Ciencias, Universidad Autónoma de Madrid, Cantoblanco, 28049 Madrid, Spain

${ }^{2}$ Unité d'Ecologie, Systématique et Evolution, UMR CNRS 8079, Université Paris-Sud, bâtiment 360, 91405 Orsay Cedex, France

\begin{abstract}
We studied the biological activity and prokaryotic diversity associated with 2 samples of different physico-chemical characteristics in a pristine coastal aquifer at Doñana National Park, south-western Spain. Sulphate reduction, denitrification and iron-metabolising activities were detected in the aquifer, as well as different enzymatic activities related to the degradation of labile and complex pools of organic matter. Prokaryotic diversity was assessed by environmental 16S rRNA gene amplification, cloning and sequencing. Bacterial diversity was greater in the shallower aquifer sample (49S1, $15 \mathrm{~m}$ depth), including members of the Proteobacteria, Acidobacteria, Planctomycetes, Nitrospirae, some divergent lineages and the candidate divisions SPAM, OP3, OP11, 'Endomicrobia' or Termite Group 1 and a novel division-level group including denitrifying bacteria associated to anaerobic methane-oxidising archaea, whereas only Proteobacteria and Firmicutes were detected in the deeper sample (56S, $80 \mathrm{~m}$ depth). By contrast, archaea seemed much more diverse in the deeper aquifer sample, with members of the Methanomicrobiales, ANME2-related Methanosarcinales and other divergent lineages, whereas only Group I Crenarchaeota were detected in the shallower sample. Betaproteobacteria were the most abundant and diverse group in both sample libraries, together with the Gammaproteobacteria in the deeper and more saline 56S sample. We detected microorganisms potentially involved in carbon, sulphur and nitrogen cycling. Interestingly, members of both aerobic (Alpha- and Gammaproteobacteria) and anaerobic methane oxidisers (ANME2 archaea) were found in the same aquifer sample.
\end{abstract}

KEY WORDS: 16S rRNA - Methane oxidation - Anammox · Nitrogen cycle - Species richness · Sulphur cycle

\section{INTRODUCTION}

In recent years, studies on aquifer microbiology have received increasing attention, as there is an important concern about the quality of natural water resources (Leclerc \& Moreau 2002). Underground aquifers serve as important sources of potable water. They include shallow, intermediate and deep aquifers, depending on their depth and their active water flow (in the order of $\mathrm{m} \mathrm{d}^{-1}$, $\mathrm{yr}^{-1}$ and century ${ }^{-1}$, respectively). They constitute the natural biotopes of subsurface microbial communities, whose diversity and ecology have also been actively studied in recent years. This is partly due to the development of molecular tools to characterise microbial diversity, particularly $16 \mathrm{~S}$ rRNA gene-based surveys, as most of these subsurface microorganisms are difficult to retrieve in culture (Ghiorse \& Wilson 1988, Pedersen 2000, Parkes et al. 2005, Schippers et al. 2005).

Most of the microbial diversity studies focusing on aquifer communities have been carried out in sites contaminated by different linear and polycyclic hydrocarbons, chlorinated compounds or heavy metals (e.g. 
Dojka et al. 1998, Takai et al. 2001, Kleikemper et al. 2002). Aquifers contaminated with organic compounds have been investigated to identify indigenous microorganisms involved in natural bioremediation aiming at prospective biotechnological applications. Early molecular diversity studies of hydrocarbon- and chlorinatedsolvent contaminated aquifers revealed the presence of microorganisms belonging to known bacterial phyla as well as divergent lineages affiliated with candidate divisions or defining novel candidate-division-level groups (Dojka et al. 1998). By contrast to hydrocarbonpolluted aquifers, organic matter is scarce in aquifers associated with deep underground systems, such as deep mines (Pedersen 2000) or the deep sub-seafloor (Fisk et al. 1998, Edwards et al. 2005). Microbial life in such systems is thought to be largely based on chemolithoautotrophy and metabolic rates may be extremely low (Parkes et al. 2005, Schippers et al. 2005).

Compared to contaminated aquifers, pristine sites have been less studied. Nevertheless, reports on the microbial diversity associated with deep aquifers, particularly of sites possessing distinctive physico-chemical characteristics such as acidic (Lehman et al. 2001), alkaline (Fry et al. 1997) or geothermal (Chapelle et al. 2002, Kimura et al. 2005) subsurface environments exist. Pristine aquifer systems can be very different according to the geological context, and among those that have attracted microbial classical and molecular studies, some flow through igneous rocks (granites and basalts; Pedersen 2001, Miyoshi et al. 2005, Ball \& Crawford 2006), others settle in sedimentary rocks, karstic environments or sandy areas (Hirsch \& RadesRohkohl 1990, Shi et al. 1999, Detmers et al. 2001, Farnleitner et al. 2005, Santoro et al. 2006).

Several studies have compared contaminated and pristine aquifers (e.g. Griebler et al. 2002). In a comparative analysis between 2 different sampling points, 1 fuel-contaminated and the other non-polluted, within the same aquifer, Shi et al. (1999) found a higher proportion of Beta- and Gammaproteobacteria in the contaminated sample. Another comparative study focusing on the long-term effect of benzene on a sandstone aquifer showed a reduced microbial diversity in contaminated compared to control sites. Multivariate statistical analyses indicated a correlation between the decrease in microbial diversity and anoxia. Rather than the toxic effect of benzene itself, anoxia caused by the microbial degradation of benzene and the decrease of available redox species were the major factors explaining the decline of microbial diversity (Fahy et al. 2005).

Although molecular surveys based on 16S rRNA and conserved metabolic genes provide insight on the phylogeny and potential activity of microorganisms that are present in the subsurface, there is little information about their actual metabolic status, as an unknown proportion of the detected phylotypes may be inactive. In the present study, we observed the microbial diversity and activities associated with a pristine coastal aquifer in the Doñana National Park, south-western Spain. Doñana is one of Europe's most important wetland reserves and is a major site for migrating birds. This area has a typical Mediterranean climate (dry and hot summer and little rainfall in winter) with some oceanic influences, broad seasonal temperature and precipitation variability, and quite stable annual variability across time. Coastal marshes represent the largest epicontinental aquatic environment in Doñana, together with several shallow lakes (López-Archilla et al. 2004), whose integrity and long-term maintenance are assured by groundwater input. Doñana's aquifer is settled in detritical deposits from the Neogene, which are covered by Quaternary fluvio-marine and eolian materials. Sands, silty sands and gravels, occasionally inter-layered with fine clay sedimentary materials, are the main components of the system (Trick \& Custodio 2004).

Doñana's aquifer is eminently freshwater, although it may be locally affected by seawater intrusion; from a hydrodynamic point of view, it is confined below the clay material, being phreatic in the upper sand layers (Custodio et al. 1995, Lozano \& Palancar 1995). In general, the phreatic level is adjusted to the topography, with an average of $6 \mathrm{~m}$ for the water table depth in many different points (Custodio et al. 1995, Lozano 2004). We report a study of 2 samples representing 2 distinct sub-systems of Doñana's aquifer (49S1 and 56S at 15 and $80 \mathrm{~m}$ depth, respectively). Microbial diversity was greater at the shallower site, which had lower mineral content, higher oxygen concentration and showed higher potential hydrolytic activities. However, the deeper site exhibited a relatively wide diversity of Euryarchaeota, with lineages clearly belonging to the anaerobic methane-oxidising archaeal group ANME2. These were identified together with phylotypes of classical aerobic methane-oxidising bacteria, suggesting that both aerobic and anaerobic methane oxidation coexist in the same aquifer samples.

\section{MATERIALS AND METHODS}

Sampling and physico-chemical measurements. Groundwater samples were collected in July 2004 from the aquifer that feeds Doñana National Park, south-western Spain, using 2 different piezometers designated 49S1 and 56S. The wells were drilled by the Guadalquivir River Water Authority in the Aeolian Littoral Mantles, a geomorphologic system formed by sand deposition in the form of active and stabilised dunes. The co-ordinates for the 2 piezometers were 
$x=721413, y=4096827$, UTM (Universal Transverse Mercator) 29 (49S1) and $x=733070, y=4087500$, UTM 29 (56S). The piezometer screen intervals were situated at a depth of $15 \mathrm{~m}$ (49S1) and between 74 and $80 \mathrm{~m}$ (56S). Groundwater samples were taken with the help of a pneumatic pump (Uwitec ${ }^{\odot}$ ) especially designed to pump the aquifer interstitial water, avoiding its mixture with the water accumulated in the piezometer. The porosity of the sand unit sustaining the aquifer corresponded to 23-38\% (Iglesias 1999). Pumped groundwater was collected from each borehole only after measurements of temperature, dissolved oxygen (DO), pH and electrical conductivity had stabilised (Haveman \& Pedersen 2002).

Physical parameters (temperature, DO, pH and electrical conductivity) were measured in situ with a WTW 340i handheld multi-parameter device, and samples for microbiological analysis were taken (see below). The piezometric level was measured in each piezometer with a water level acoustic indicator (Nordmeyer). For chemical determinations (alkalinity, ammonium, nitrate, nitrite, soluble reactive phosphorus [SRP], total phosphorus concentration), samples were stored in triplicate in polyurethane or glass bottles, previously treated with $5 \% \mathrm{HCl}$ and washed with distilled water, and then kept frozen or refrigerated until laboratory analyses were done. Chemical analyses were carried out using standard methods (APHA et al. 1989). Alkalinity was measured during the same sampling day. Ferrous and ferric ions, as well as the total iron concentration, were determined in the laboratory by the ferrozine colorimetric method (Viollier et al. 2000); samples were stabilised with $\mathrm{HCl}$ (0.12 N final concentration) until the analysis was done. Various water samples were collected carefully in sterile containers to prevent possible external contamination and were conditioned in the appropriate ways (see below) for subsequent microscopy, enzymatic and molecular biology analyses in the laboratory.

Biological parameters and enzymatic assays. For epifluorescence microscopy observations, groundwater samples from each piezometer were collected and fixed with formaldehyde (4\% v/v final concentration) in $100 \mathrm{ml}$ polyurethane bottles (pre-treated with $\mathrm{HCl}$ and rinsed with distilled water, as above) in triplicate; these samples were stored in the dark at $4^{\circ} \mathrm{C}$ until further analysis. Water samples were filtered through $0.2 \mu \mathrm{m}$ GTBP membrane filters (Millipore GTBP02500), and cells were counted by epifluorescence microscopy observation after staining with 4',6-diamidino-2phenylindole-dihydrochloride (DAPI; Fry 1990). Single cell biovolumes were estimated with the aid of an ocular micrometer under an Olympus IX50 inverted microscope to measure the lengths and widths of cells at a magnification of $1000 \times$ on the same filters from which their abundance was determined. Cell biovolumes were calculated assuming that cells were spheres or cylinders with hemispheres on both sides. Linear dimensions were converted to volumetric ones using geometric formulas and the single cell biomass calculated from single cell biovolumes using the allometric model conversion factor: $C=120 V^{0.7}$, where $C$ is cell biomass (fg C) and $V$ is cell biovolume $\left(\mu \mathrm{m}^{3}\right)$ (Bölter et al. 2002).

Water samples to estimate microbial activity, productivity as deduced from the leucine incorporation rate, enzymatic activity, bacterial functional groups and community diversity studies were collected in sterile glass bottles, stored at $4{ }^{\circ} \mathrm{C}$ and transported to the laboratory. Microbial activity was estimated using an ATPbased method on triplicate groundwater samples collected in $20 \mathrm{ml}$ bottles. ATP assays were carried out during the same sampling day. ATP was extracted using a commercial kit (BioThema) and quantified via the luciferin-luciferase enzyme assay using a Berthold Junior LB9509 luminometer, with a detection limit of approximately $10 \times 10^{-18} \mathrm{~mol}$ ATP. For each assay, ATP was extracted from $50 \mu$ groundwater following the manufacturer's instructions. Duplicate autoclaved water samples were used as controls for each assay. The relative light units (RLU) measured with the luminometer were converted into ATP concentration values using a regression equation calculated with an ATP standard provided in the same commercial kit. To estimate the active biomass, we applied the conversion factor: $1 \mathrm{ng}$ ATP $\mathrm{l}^{-1}=250 \mathrm{ng} \mathrm{C} \mathrm{l}^{-1}$ (Karl 1980).

Microbial productivity was estimated by measuring the incorporation of ${ }^{3} \mathrm{H}$-leucine into cellular proteins (Kirchman et al. 1985). Three replicates and 2 controls were analysed for each piezometer. ${ }^{3} \mathrm{H}$-leucine (37 MBq mol ${ }^{-1}$; Amersham Pharmacia Biotech) was added to $10 \mathrm{ml}$ groundwater to a final concentration of $11 \mathrm{nM}$, and incubated for $1 \mathrm{~h}$ at $20^{\circ} \mathrm{C}$. Leucine incorporation was stopped with $1.1 \mathrm{ml}$ of formaldehyde, and samples were frozen $\left(-20^{\circ} \mathrm{C}\right)$ until protein extraction. Insoluble protein material was precipitated with hot trichloroacetic acid and collected on cellulose filters (Kirchman et al. 1985). Incorporated radioactivity was measured after addition of scintillation cocktail in a Wallack 1209 Rackbeta Liquid Scintillation Counter (LKB). Microbial productivity was then estimated according to the equation: Productivity $=\mathrm{LI} \times 131.2 \times$ $0.073 \times(\mathrm{C} /$ protein $) \times \mathrm{ID}$, where LI is the leucine incorporation rate $\left(\mathrm{mol} \mathrm{l}^{-1} \mathrm{~h}^{-1}\right), 131.2$ is the molecular weight of leucine, 0.073 is the average percentage of leucine in cell proteins, C/protein is the ratio of cellular carbon to protein (0.86) and ID is the isotope dilution (both external and internal), which is assumed not to have taken place in this study (Simon \& Azam 1989).

The enzymatic activities of $\beta$-D-glucosidase, leucine aminopeptidase, phenol oxidase and alkaline phosphatase were assayed by incubation with pNP- $\beta$-D- 
glucopyranoside, leucine p-nitroanilide, L-3,4-dihydroxyphenylalanine (L-DOPA) and pNP-phosphate, respectively. All substrates were obtained from Sigma. Assays for $\beta$-D-glucosidase and phenol oxidase were conducted at $20^{\circ} \mathrm{C}$ in $50 \mathrm{mM}$ acetate buffer, $\mathrm{pH}$ 5.0, under previously determined substrate saturating conditions. For alkaline phosphatase and leucine aminopeptidase, assays were conducted in $5 \mathrm{ml}$ reaction volumes with $50 \mathrm{mM}$ Tris- $\mathrm{HCl}, \mathrm{pH} 8.5$, under previously determined substrate saturating conditions. In all cases, 3 analytical replicates and duplicate controls were carried out. A more detailed description of the procedures used can be found in (Sinsabaugh et al. 1994).

Different microbial functional activities revealing the presence of nitrifying, sulphate-reducing, denitrifying and iron-metabolising microorganisms were assayed using Biological Activity Reaction Tests (BART $^{\mathrm{TM}}$, LaMotte; Cullimore 1993). Tests are done at room temperature and consist of the inoculation of a sample in a culture tube with the particular medium assayed that contains a colour indicator shifting upon a redox change. A ball is placed on top of the water column that restricts the amount of oxygen entering it, so that aerobic organisms grow around the ball and anaerobic organisms grow deep down in the water column. If the type of organisms tested is present in the sample, the indicator will change colour, indicating that the targeted reaction has taken place. These tests are semi-quantitative, allowing not only the detection of a given activity but also providing an indication of the level of activity. In our case, the presence of the above functional groups was determined in $10 \mathrm{ml}$ groundwater samples from each piezometer.

DNA extraction, PCR amplification, cloning and sequencing. For molecular diversity estimates, $1 \mathrm{l}$ of each groundwater sample was filtered across $0.22 \mu \mathrm{m}$ pore diameter GTTP filters (Millipore), which were stored at $-20^{\circ} \mathrm{C}$ until nucleic acids were extracted. Filters were washed extensively with phosphate saline buffer (130 mM NaCl, $10 \mathrm{mM}$ phosphate buffer, $\mathrm{pH}$ $7.4)$ to resuspend the retained biomass. Subsequently, lysis proceeded by the addition of $80 \mathrm{\mu g} \mathrm{ml}^{-1}$ Proteinase $\mathrm{K}, 1 \% \mathrm{SDS}, 1.4 \mathrm{M} \mathrm{NaCl}, 0.2 \% \beta$-mercaptoethanol and $2 \% \mathrm{CTAB}$ (final concentrations) and incubation of the samples overnight at $55^{\circ} \mathrm{C}$. DNA from lysates was extracted sequentially with hot phenol $\left(65^{\circ} \mathrm{C}\right)$, phenol-chloroform-isoamyl-alcohol, and chloroform-isoamyl-alcohol. Nucleic acids were concentrated by salt and ethanol precipitation. Nucleic acids were resuspended in $10 \mathrm{mM}$ Tris- $\mathrm{HCl}, \mathrm{pH}$ 8.0. 16S rRNA genes were subsequently amplified by PCR using different combinations of bacterial (B-), archaeal (A-) and prokaryotic-specific primers: B-27F (AGAG TTTGATCCTGGCTCAG), A-23FLP (GCGGATCCGC GGCCGCTGCAGAYCTGGTYGATYCTGCC), Ar109F
(ACSGCTGCTCAGTAACACGT), A-ANMEF (GGCT CAGTAACACGTGGA) and 1492R (GGTTACCTTGTTACGACTT). PCR reactions were performed under the following conditions: 2 min denaturation at $94^{\circ} \mathrm{C}$; 30 cycles of denaturation at $94^{\circ} \mathrm{C}$ for $15 \mathrm{~s}$, annealing at 50 to $55^{\circ} \mathrm{C}$ for $30 \mathrm{~s}$, extension at $72^{\circ} \mathrm{C}$ for $2 \mathrm{~min}$; and 7 min extension at $72^{\circ} \mathrm{C}$. Dimethyl sulphoxide was added to a final concentration of 3 to $5 \%$ to the PCR reaction mix. 16S rRNA gene clone libraries were constructed using the Topo TA Cloning system (Invitrogen) following the instructions provided by the manufacturer. Three 16S rRNA gene libraries were constructed for the archaea ( 2 for $49 \mathrm{~S} 1$ and 1 for $56 \mathrm{~S}$ ), and another three for bacteria ( 2 for 49S1 and 1 for 56S). After plating, positive transformants were screened by PCR amplification of inserts using M13R and T7 flanking vector primers, and positive clones were sequenced by Genome Express (Meylan) with the PCR amplification primers used in each case. Partial sequences (600 to $800 \mathrm{bp}$ ) of good quality were retained for subsequent analyses: 71 and 90 bacterial sequences, and 19 and 21 archaeal sequences from 49S1 and 56S, respectively, for a total of 201 sequences (Table 2). From these, a total of 75 clones representative of the diversity found (representing groups of sequences with $>97 \%$ identity, see Appendix 1, available as supplementary material at www.intres.com/articles/suppl/a047p123_app.pdf) were fully sequenced in order to carry out detailed phylogenetic analyses: 44 and 19 bacterial clones, and 4 and 8 archaeal ones, from 49S1 and 56S, respectively.

Biodiversity estimates. Rarefaction curves and different biodiversity indices were estimated from our sequence data using the program DOTUR (Schloss \& Handelsman 2005). Prokaryotic high-quality partial sequences were aligned using ClustalX (Thompson et al. 1997) for 49S1 (15 m depth) and 56S (80 m depth) independently, and the respective distance matrices were generated in Phylip format after excluding gaps. The resulting matrices were used as input for DOTUR in order to generate rarefaction curves at $97 \%$ sequence identity level, corresponding roughly to the species level, lineage-through-time plots, and different species richness indicators considering $97 \%$ (species) and $95 \%$ (genus level) threshold values for the definition of operational taxonomic units (OTUs; see Table 2). The homologous and heterologous coverage of the 2 sets of libraries (for 49S1 and 56S, respectively) as a function of phylogenetic distance was compared using the program LIBSHUFF (Singleton et al. 2001).

Phylogenetic analyses. Alignment and preliminary distance phylogenetic analysis of the 205 partial 16S rRNA gene sequences were done using ClustalX. This allowed the identification of identical or nearly identical sequences and the selection of clones for complete 
sequencing. The 75 representative clones that were completely sequenced, together with their closest homologues in GenBank (http://ncbi.nlm.nih.gov/) as detected by BLAST (Altschul et al. 1997), were aligned automatically with an alignment containing 16000 16S rRNA gene sequences using the program BABA (H. Philippe pers. comm.). The multiple alignment was then manually edited using the program ED from the MUST package (Philippe 1993). Neighbour-joining (NJ) trees were constructed for the different prokaryotic taxa in order to choose representative subsets of sequences for further phylogenetic analyses. Gaps and ambiguously aligned positions were excluded from our analyses using strict criteria, which resulted in alignments of variable length (positions). Four different subsets of 16S rRNA gene sequences were selected to ensure good taxonomic coverage of different regions in phylogenetic trees. These subsets were: Archaea (49 sequences, 848 positions), overall bacterial phylogeny including candidate divisions (91 sequences, 1092 positions), Beta- + Gammaproteobacteria (94 sequences, 1238 positions), and Alpha- + Deltaproteobacteria (49 sequences, 1187 positions). These datasets were analysed by maximum likelihood (ML) using TREEFINDER (www. treefinder.de) applying a general time reversible (GTR) model of sequence evolution, and taking among-site rate variation into account by using a 6 -category discrete approximation of a $\Gamma$ distribution (invariable sites are included in one of the categories). ML bootstrap proportions were inferred using 1000 replicates. Phylogenetic trees were viewed using the program TREEVIEW (Page 1996). The sequences reported in this study were submitted to GenBank under accession numbers DQ837222 to DQ837296 (see also Figs. 3 to 5 and Appendix 1).

\section{RESULTS AND DISCUSSION}

\section{Physico-chemical characteristics of sampling sites}

A preliminary study of the physicochemical and biological characteristics of various samples collected from a variety of piezometers placed at 30 different sites and depths in Doñana National Park had revealed the presence of 2 types of samples that shared, respectively, very similar and homogeneous characteristics (S. Velasco \& A. I López-Archilla unpubl.). They corresponded to 2 distinct sub-systems in the aquifer, one lying below the sand dunes and characterised by low-mineral waters, and the other richer in minerals, below the salt marshes. We therefore selected 1 representative sample of each, namely 49S1 and 56S, for further analysis.

We measured various physico-chemical parameters and collected samples for biological analyses from the 2 selected piezometers. Piezometer 49S1 was placed at $15 \mathrm{~m}$ depth and approximately $2 \mathrm{~km}$ from the shoreline, and $56 \mathrm{~S}$ at approximately $80 \mathrm{~m}$ depth and $0.5 \mathrm{~km}$ from shore. The physico-chemical characteristics of the 2 aquifer samples were quite different. The shallower site, 49S1, was more acidic ( $\mathrm{pH} \mathrm{5.17)}$ and with less alkalinity (0.5 meq $\mathrm{l}^{-1}$ ), and contained lower inorganic nutrient concentrations, including SRP, nitrite, nitrate, ammonium and iron (Table 1). By contrast, 56S had neutral $\mathrm{pH}(7.45)$ and higher alkalinity $\left(6 \mathrm{meq}^{-1}\right)$, as

Table 1. Physico-chemical and biological parameters measured in the $15 \mathrm{~m}$ deep (49S1) and $80 \mathrm{~m}$ deep (56S) samples collected from the coastal freshwater aquifer in Doñana National Park, Spain. SRP: soluble reactive phosphorus; ND: not determined. ++, +++: increasing growth yield; -: no growth

\begin{tabular}{|c|c|c|}
\hline & $49 \mathrm{~S} 1$ & $56 \mathrm{~S}$ \\
\hline Sampling depth (m) & 15 & $74-80$ \\
\hline $\mathrm{T}\left({ }^{\circ} \mathrm{C}\right)$ & $19.2 \pm 0.1$ & $22.1 \pm 0.1$ \\
\hline Phreatic level $^{\mathrm{a}}(\mathrm{m})$ & 3.06 & 1.64 \\
\hline Dissolved oxygen $\left(\mathrm{mg} \mathrm{l}^{-1}\right)$ & $1.13 \pm 0.06$ & $0.86 \pm 0.00$ \\
\hline $\mathrm{pH}$ & $5.17 \pm 0.14$ & $7.45 \pm 0.03$ \\
\hline Electric conductivity $\left(\mathrm{mS} \mathrm{cm}^{-1}\right)$ & $0.15 \pm 0.02$ & $21.01 \pm 0.15$ \\
\hline Total alkalinity (meq l-1) & $0.523 \pm 0.023$ & $6.000 \pm 0.000$ \\
\hline$\left[\mathrm{N}-\mathrm{NH}_{4}\right]\left(\mathrm{mg} \mathrm{l}^{-1}\right)$ & $1.22 \pm 0.09$ & $7.78 \pm 1.39$ \\
\hline$\left[\mathrm{N}-\mathrm{NO}_{2}^{-}\right]\left(\mathrm{mg} \mathrm{l}^{-1}\right)$ & $0.004 \pm 0.007$ & $0.000 \pm 0.000$ \\
\hline$\left[\mathrm{N}-\mathrm{NO}_{3}^{-}\right]\left(\mathrm{mg} \mathrm{l}^{-1}\right)$ & $0.339 \pm 0.071$ & $0.431 \pm 0.034$ \\
\hline$\left[\mathrm{Fe}^{2+}\right]\left(\mathrm{mg} \mathrm{l}^{-1}\right)$ & $0.051 \pm 0.015$ & $0.122 \pm 0.083$ \\
\hline$\left.\left[\mathrm{Fe}^{3+}\right]\left(\mathrm{mg} \mathrm{l}^{-1}\right)\right)$ & $0.379 \pm 0.242$ & $1.317 \pm 0.724$ \\
\hline Total [Fe] $\left(\mathrm{mg} \mathrm{l}^{-1}\right)$ & $0.430 \pm 0.255$ & $1.439 \pm 0.648$ \\
\hline$[\mathrm{P}-\mathrm{SRP}]\left(\mathrm{mg} \mathrm{l}^{-1}\right)$ & $0.002 \pm 0.000$ & $0.423 \pm 0.041$ \\
\hline$[\mathrm{P}-\mathrm{Pt}]\left(\mathrm{mg} \mathrm{l}^{-1}\right)$ & $0.013 \pm 0.001$ & $0.521 \pm 0.041$ \\
\hline Total [P] $\left(\mathrm{mg} \mathrm{l}^{-1}\right)$ & $0.039 \pm 0.001$ & $1.598 \pm 0.125$ \\
\hline Active biomass ${ }^{\mathrm{b}}\left(\mathrm{g} \mathrm{C} \mathrm{ml}^{-1}\right)$ & ND & $3.810^{-7} \pm 1.110^{-7}$ \\
\hline Cell density $\left(10^{7}\right.$ cell ml $\left.{ }^{-1}\right)$ & $9.30 \pm 8.74$ & $9.34 \pm 8.15$ \\
\hline Cell volume $\left(\mu \mathrm{m}^{3}\right)$ & $0.78 \pm 0.89$ & $1.05 \pm 1.04$ \\
\hline Cell biomass (fgC) & $89.97 \pm 72.15$ & $114.62 \pm 76.00$ \\
\hline $\mathrm{C}$ incorporation $\left(10^{-8} \mathrm{~g} \mathrm{C} \mathrm{h}^{-1} \mathrm{l}^{-1}\right)$ & $2.8 \pm 2.0$ & $0.3 \pm 0.2$ \\
\hline Aminopeptidase activity $\left(\mathrm{nmol} \mathrm{h}^{-1} \mathrm{ml}^{-1}\right)$ & $0.004 \pm 0.012$ & $0.001 \pm 0.002$ \\
\hline Phosphatase activity $\left(\mathrm{nmol} \mathrm{h}^{-1} \mathrm{ml}^{-1}\right)$ & $0.616 \pm 0.182$ & $0.003 \pm 0.006$ \\
\hline Glucosidase activity ${ }^{\mathrm{c}}\left(\mathrm{nmol} \mathrm{h}^{-1} \mathrm{ml}^{-1}\right)$ & $0.738 \pm 0.557$ & $0.000 \pm 0.000$ \\
\hline Phenol-oxidase activity ${ }^{\mathrm{c}}\left(\mathrm{nmol} \mathrm{h}^{-1} \mathrm{ml}^{-1}\right)$ & $2.869 \pm 1.650$ & $5.348 \pm 0.661$ \\
\hline Sulphate reduction (BART) & ++ & +++ \\
\hline Nitrification (BART) & - & - \\
\hline Denitrification (BART) & ++ & +++ \\
\hline Iron-metabolising (BART) & ++ & +++ \\
\hline \multicolumn{3}{|c|}{$\begin{array}{l}{ }^{a} \text { Groundwater table } \\
{ }^{b} \text { Estimated by the ATP method (see 'Materials and methods') } \\
{ }^{c} \text { nmol of transformed substrate } \mathrm{h}^{-1} \mathrm{ml}^{-1}\end{array}$} \\
\hline
\end{tabular}


well as higher concentrations of inorganic nutrients (Table 1). The presence of relative high levels of $\mathrm{Fe}^{3+}$ in the samples is due to the occurrence of a deeper layer of red sands rich in iron oxides (red formation) that is washed by the up-welling water flux (Trick \& Custodio 2004). The 2 sites were suboxic, although 56S was closer to anoxia than 49S1 (oxygen concentration of 0.86 vs. $1.13 \mathrm{mg} \mathrm{l}^{-1}$, respectively). Notably, conductivity values were far higher in $56 \mathrm{~S}\left(21 \mathrm{mS} \mathrm{cm}^{-1}\right)$ than in 49S1 $\left(0.15 \mathrm{mS} \mathrm{cm}^{-1}\right)$, being intermediate between typical freshwater and seawater levels $\left(41.5 \mathrm{mS} \mathrm{cm} \mathrm{cm}^{-1}\right)$. This reveals the marine influence due to the greater depth of the 56S piezometer and its closest location to the seashore.

\section{Biological parameters and enzymatic activities}

Cell density was similar in both aquifer samples, although the error bars for these measurements were important due to the small cell size and to the unspecific DAPI staining of some tiny sediment particles suspended in the sample. Despite similar cell densities, both aquifer samples showed different biological activities, as shown by BARTs and enzymatic assays. It is important to note that these activities are tested in the laboratory by incubation of aquifer samples and therefore indicate only potential metabolic activities taking place in situ. The biological heterotrophic activity in the deepest sample was smaller, as the incorporation rate of ${ }^{3} \mathrm{H}$-leucine was more important in 49S1 than in 56S. By contrast, 56S displayed greater sulphate reduction, denitrification and iron-metabolising activities as revealed by the BARTs (see 'Materials and methods' and Table 1). The phenol-oxidase activity, which is related to the degradation of recalcitrant organic matter fractions (Sanderman \& Amundson 2005), was also higher in 56S. In contrast, 49S1 samples displayed higher phosphatase, aminopeptidase and glucosidase activities (Table 1), which are involved in the degradation of nucleic acids, polypeptides and linear carbohydrates constituting the easiest accessible fractions of organic matter that are first consumed (labile pool). A higher phenol-oxidase activity in deeper aquifer layers would be in agreement with the consumption of simpler organic matter in upper layers, while only the more complex, aromatic-rich, organic compounds percolate to greater depths. Although cell density was similar in both aquifer samples, cells observed in 56S samples appeared to be relatively larger and therefore constitute more biomass compared to those from 49S1 (Table 1). However, since the standard deviations for these values were high, this observation would need further confirmation. The average cell size was 0.8 to $1 \mu^{3}$ for both aquifer samples, which is in the range of cell volumes reported in the literature for other aquifer samples $(0.03$ to $1.14 \mathrm{\mu m}^{3}$; e.g. Balkwill \& Ghiorse 1985, Bernard et al. 2000, Griebler et al. 2002). This is not surprising, since the size of microorganisms inhabiting groundwater is usually small, including, notably, a large diversity of organisms that pass through $0.2 \mu \mathrm{m}$ pore filters (Miyoshi et al. 2005). In order to identify the microbial lineages that might be responsible for the biological activities measured in the 2 aquifer samples, we subsequently carried out a molecular survey of the prokaryotic components of the aquifer's microbial communities.

\section{Overall phylogenetic diversity and diversity estimates}

We purified nucleic acids from 49S1 and 56S samples and then amplified and cloned 16S rRNA genes using different combinations of archaeal- and bacterial-specific primers. The different 16S rRNA gene libraries were screened and a total of 201 partial sequences generated $(71$ and 90 bacterial sequences, and 19 and 21 archaeal sequences from 49S1 and 56S, respectively). We compared them by BLAST to sequences deposited in GenBank to assess the phylogenetic diversity present in our samples (Fig. 1 and Appendix 1). Subsequently, 75 representative clones were completely sequenced in order to carry out detailed phylogenetic analyses (see below). The bacterial diversity was greater in 49S1 than in 56S libraries, with members of up to 9 different bacterial phyla or candidate divisions and a few very divergent phylotypes of uncertain affiliation (Fig. 1). Taxa identified in 49S1 included the Proteobacteria, with representatives of the Alpha-, Beta-, Gamma- and Delta- subdivisions, Planctomycetes, Acidobacteria, Nitrospirae and the candidate divisions or phyla 'Endomicrobia', SPAM, OP11, OP3 and a novel division-level group of bacteria, some of whose members appear to be denitrifying microorganisms forming syntrophic consortia with anaerobic methane-oxidising archaea (Raghoebarsing et al. 2006). 'Endomicrobia' is a candidate phylum corresponding to the candidate division Termite Group 1, whose members have been retrieved mostly from termite guts (Stingl et al. 2005). By contrast, only members of 2 bacterial phyla (Proteobacteria and Firmicutes) were amplified from the 56S sample. In both aquifer samples, the dominant group in libraries was that of the Betaproteobacteria, which is frequently and abundantly detected in groundwater (Miyoshi et al. 2005, Santoro et al. 2006), although the Gammaproteobacteria were also very abundant in the 56S library. Despite the fact that the phylum-level bacterial diversity appeared greater in the shallower 49S1, the archaeal diversity appeared wider in 56S (see below). 


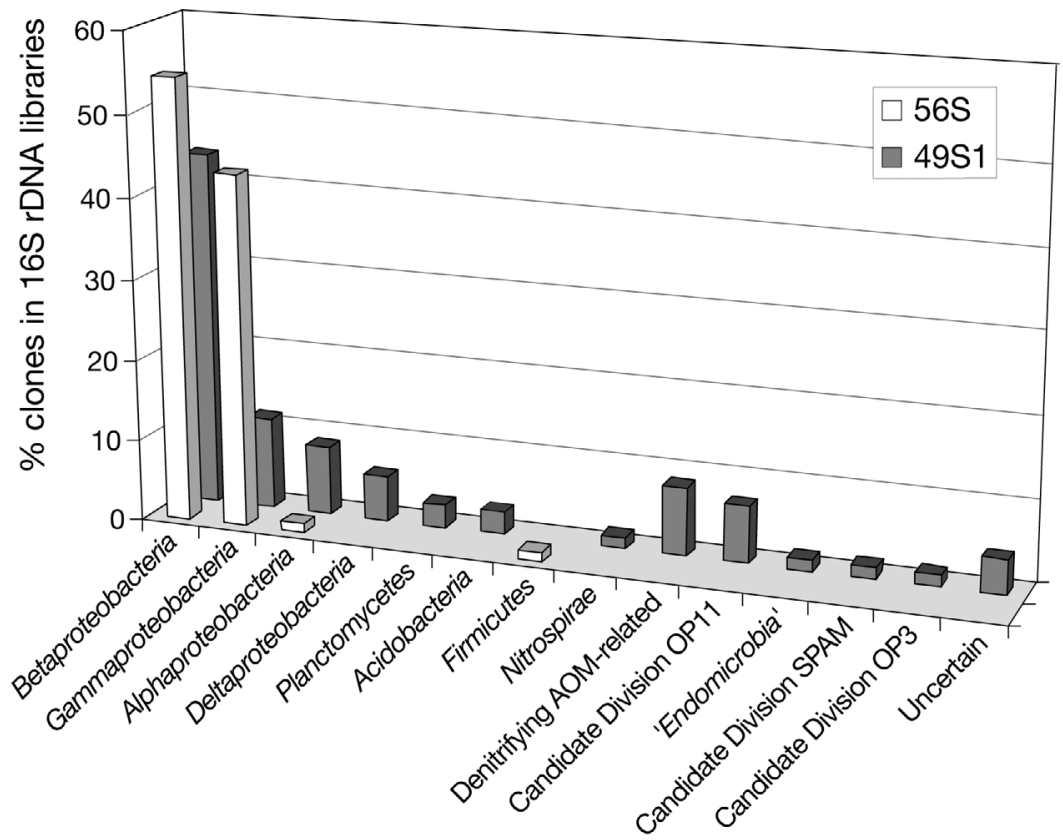

Fig. 1. Distribution in major phylogenetic groups of $16 \mathrm{~S}$ rRNA bacterial genes of the $15 \mathrm{~m}$ deep (49S1) and $80 \mathrm{~m}$ deep (56S) samples collected from the coastal freshwater aquifer in Doñana National Park, Spain. Denitrifying-AOM-related corresponds to the novel division-level group proposed by Raghoebarsing et al. (2006) including the bacterial symbiont of a denitrifying AOM consortium. AOM: anaerobic oxidation of methane. 'Endomicrobia' is a candidate phylum equivalent to the Candidate Division Termite Group 1 tively high in 49S1 at the species level, being moderate in $56 \mathrm{~S}$. This trend was also observed when considering the genus-level approximation $(95 \%$ sequence identity). However, it is difficult to compare with other environmental studies of aquifers, since diversity measurements are not usually estimated. We also represented the evolution of the non-parametric species richness estimators Chao1 and abundancebased coverage estimators (ACE) as a function of the number of sequencs sampled (Fig. 2C). Both indices yielded similar OTU estimations and, again, estimates were higher for 49S1 than for 56S. In addition, we constructed a square distance matrix including the sequences from the 2 libraries to determine whether they were significantly different. The comparison of the homologous $\left(C_{49 \mathrm{~S} 1}\right)$ versus the heterologous $\left(C_{49 \mathrm{~S} 1 / 56 \mathrm{~S}}\right)$ coverage (Singleton et al. 2001) showed that the 2 sets of libraries were indeed significantly different $\left(\Delta C_{49 \mathrm{~S} 1 / 56 \mathrm{~S}}=0.002, \mathrm{p}=0.001\right)$.
To gain insight into the degree of exploration of the 16S rRNA gene libraries constructed from the 2 aquifer samples, we made rarefaction curves and estimated different diversity indices. We produced 2 independent alignments, corresponding to the complete sets of partial sequences retrieved from 49S1 and 56S, respectively. We then generated the respective distance matrices to produce accurate estimates of the level of phylotype redundancy (rarefaction curves) and to calculate various diversity indices based on the proportional number of species (see 'Materials and methods'). As a practical criterion to define prokaryotic species or, rather, an OTU, we considered those sequences having more than $97 \%$ identity as members of the same OTU (Schloss \& Handelsman 2005). Rarefaction curves for 49S1 and 56S did not reach saturation, although 56S was much closer to it as the curve seemed to approach an asymptote (Fig. 2A). In the lineage-through-time plots (Schloss \& Handelsman 2005), the 49S1 curve was also above that of $56 \mathrm{~S}$, indicating that there were consistently higher numbers of 49S1 than 56S OTUs at different phylogenetic distances (Fig. 2B). The greater diversity in 49S1 libraries was also reflected by higher values in all diversity estimates done (Table 2). Thus, the Shannon index, widely used to compare OTU richness in different samples, was rela-

\section{Archaeal community composition}

We detected members of both archaeal kingdoms, Crenarchaeota and Euryarchaeota, in Doñana National Park. However, they appeared to be distinctly distributed, with members of the Crenarchaeota only detected in the shallower 49S1 sample and members of the Euryarchaeota exclusively in the deeper 56S sample. From the 40 partial sequences analysed, we completely sequenced 12 clones representative of the archaeal diversity found. All crenarchaeotal phylotypes belonged to the mesophilic Group I, which is largely distributed in marine, freshwater and soil samples. Most of our phylotypes clustered with environmental sequences retrieved from soil and from deep aquifers or mines (Fig. 3 and Appendix 1) (Takai et al. 2001, Kimura et al. 2005), with the exception of Doñana 49S-2A-3, whose closest neighbour was a sequence retrieved from $770 \mathrm{~m}$ deep plankton in the Pacific Hawaii Ocean Timeseries (HOT) station (DeLong et al. 2006). The lifestyle of Group I Crenarchaeota was elusive for a long time, although, based on the incorporation of labelled bicarbonate during in situ incubation experiments, an autotrophic metabolism has been postulated (Wuchter et al. 2003). The discovery of amo-related genes in genome fragments of soil Crenarchaeota led to the suspicion that they 

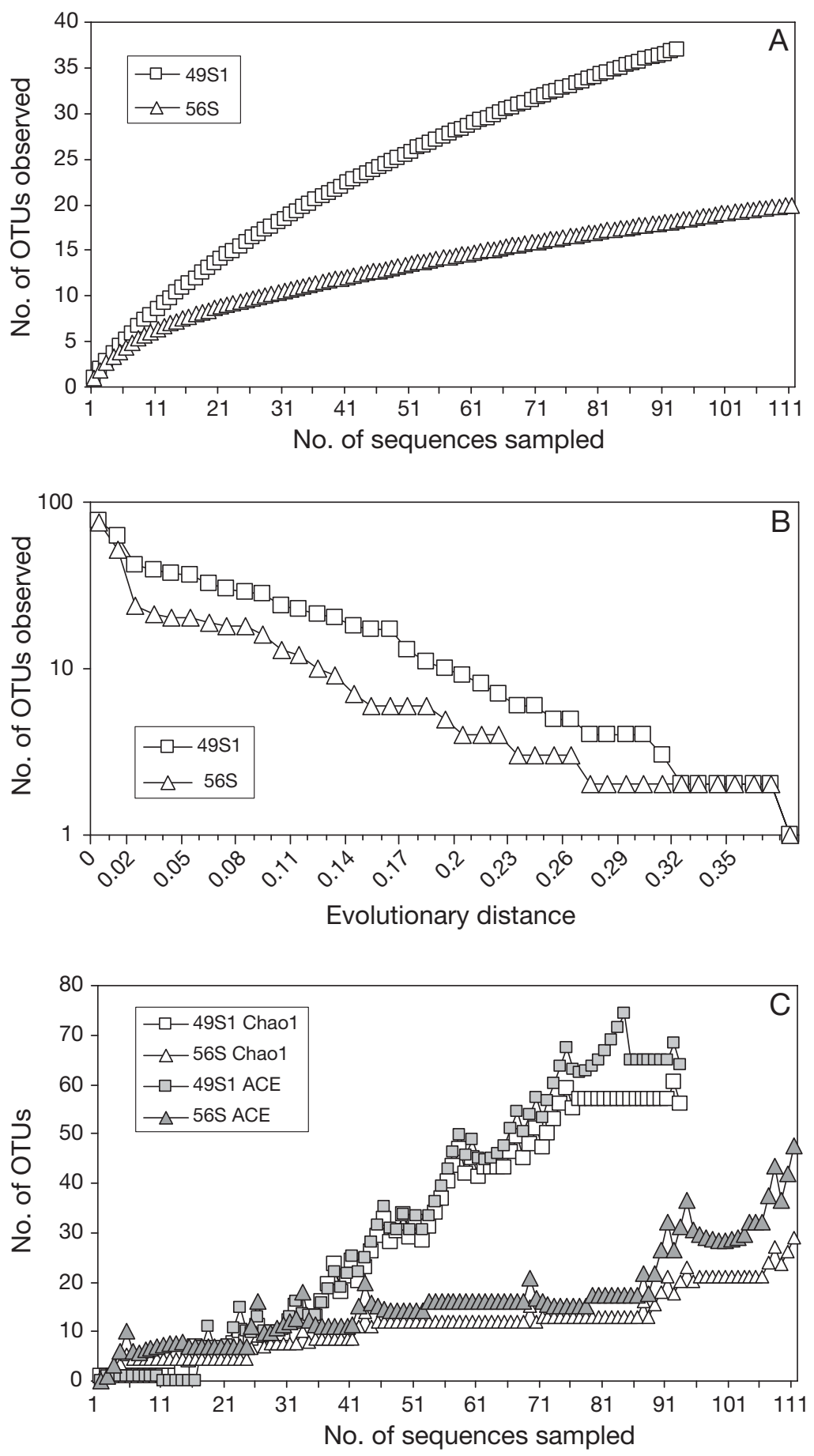

Fig. 2. (A) Rarefaction curves, (B) lineage-through-time plots and (C) Chao1 and ACE richness estimate collector's curves for aquifer samples 49S1 and 56S from Doñana National Park. Rarefaction curves and Chao1 richness estimate collector's curves were calculated for OTUs defined as groups of sequences with $>97 \%$ identity (species level)

could oxidise ammonia (Venter et al. 2004, Francis et al. 2005, Schleper et al. 2005, Treusch et al. 2005) and, recently, this was confirmed by the isolation of Nitrosopumilus maritimus, an autotrophic ammonia- oxidising crenarchaeote (Konneke et al. 2005). The fact that the rest of Group I Crenarchaeota also display this type of metabolism cannot be assured with certainty. Nevertheless, the fact that various metagenomic crenarchaeote fragments contain amo-related genes suggests that this may be the case and that a large proportion of these archaea do play a key role in the nitrogen cycle (Nicol \& Schleper 2006).

Although the bacterial diversity in 56S was relatively limited in terms of detected phyla and the only archaea found were Euryarchaeota, these were highly diverse. 56S archaeal phylotypes were scattered in the euryarchaeotal tree, with phylotypes belonging to welldefined groups such as the Methanomicrobiales and the Methanosarcinales, but also to groups of environmental sequences (Fig. 3). In all cases, the closest relatives of our phylotypes were sequences retrieved from environments highly reduced or with strong redox gradients, such as mud volcanoes, hydrothermal sediments, cold seeps or sulphide springs (Fig. 3. and Appendix 1). Some of them were identified in hydrocarbon- and chlorinated-solvent contaminated aquifers (Dojka et al. 1998). The metabolic capacities of the Thermoplasmatales-related and other divergent euryarchaeotal lineages cannot be inferred at present. By contrast, the phylotype Doñana 56S-3A-18, well nested within the Methanomicrobiales, is most likely a methanogen, since all cultivated Methanomicrobiales are methanogens. Similarly, we can reasonably infer the metabolism of the phylotypes belonging to the Methanosarcinales. Although many Methanosarcinales are methanogens, members of various clusters forming the large ANME2 group are methanotrophic, possibly by performing reverse methanogenesis (Hallam et al. 2004), in syntrophy with sulphate-reducing bacteria (Boetius et al. 2000, Orphan et al. 2001a). Our phylotypes Doñana 56S-3A36 and Doñana 56S-3A-21, the most represented euryarchaeotal clone in our library (Appendix 1), were very closely related to other ANME2 members, strongly suggesting that they might be anaerobic methanotrophs. 


\section{General bacterial diversity}

The bacterial diversity was greater in 16S rRNA gene libraries from the shallowest Doñana aquifer sample, 49S1. The 71 partial 49S1 sequences distributed in various phyla and candidate divisions, whereas of the 90 partial 56S sequences, only 1 belonged to a phylum different from the Proteobacteria, the Firmicutes (Fig. 1). Clones representative of the Proteobacteria (see following section) and the rest of the detected bacterial phyla or candidate divisions (Fig. 4) were fully sequenced for detailed phylogenetic analyses. Phylotypes belonging to phyla other than the Proteobacteria and the Firmicutes were only identified in 49S1. Some clones affiliated to phyla with cultivated representatives, namely Planctomycetes, Acidobacteria and Nitrospirae, but most of them belonged to candidate divisions without cultivated members (Fig. 1). The closest relative of Planctomycetes-related sequences from Doñana was the uncultured anaerobic ammonium-oxidising bacterium Kuenenia stuttgartiensis. As revealed from a recent metagenomic analysis, K. stuttgartiensis appears highly versatile with respect to energy metabolism (Strous et al. 2006). The presence of related sequences in Doñana's pristine aquifer might indicate the occurrence of anammox bacteria, which are key players in nitrogen cycling, in suboxic subsurface environments. We also detected a phylotype (49S1-2B-27) closely related to a sequence from a deep igneous aquifer that belonged to the Nitrospirae, a phylum including the nitrite-oxidising genus Nitrospira (Fig. 4). Although the Nitrospirae include metabolically diverse bacteria, nitrite oxidation is widespread in this group, and Doñana 49S1-2B27 appears indeed related to environmental lineages of nitrite-oxidising Nitrospirae (Daims et al. 2001), although this metabolic activity cannot be directly inferred. The other bacterial phylum with cultivated

Table 2. Prokaryotic species richness estimates at different levels of operational taxonomic unit sequence identity in 49S1 and 56S samples from the coastal aquifer of Doñana National Park. CI: confidence interval

\begin{tabular}{|c|c|c|c|c|}
\hline & \multicolumn{2}{|c|}{ 49S1 (15 m depth) } & \multicolumn{2}{|c|}{ 56S (74-80 m depth) } \\
\hline $\begin{array}{l}\text { Total no. of } \\
\text { sequences }\end{array}$ & \multicolumn{2}{|c|}{94} & \multicolumn{2}{|c|}{111} \\
\hline $\begin{array}{c}\text { No. of unique } \\
\text { sequences }\end{array}$ & \multicolumn{2}{|c|}{78} & \multicolumn{2}{|c|}{76} \\
\hline Diversity indices & $\begin{array}{c}97 \% \text { identity } \\
\pm \text { CI }(5 \%)\end{array}$ & $\begin{array}{c}95 \% \text { identity } \\
\pm \text { CI }(5 \%)\end{array}$ & $\begin{array}{c}97 \% \text { identity } \\
\pm \text { CI }(5 \%)\end{array}$ & $\begin{array}{c}95 \% \text { identity } \\
\pm \mathrm{CI}(5 \%)\end{array}$ \\
\hline Simpson & 0.06 & 0.07 & 0.13 & 0.14 \\
\hline Shannon & $3.13 \pm 0.23$ & $2.99 \pm 0.22$ & $2.29 \pm 0.20$ & $2.23 \pm 0.23$ \\
\hline $\mathrm{ACE}$ & $64 \pm 29$ & $64 \pm 27$ & $47 \pm 32$ & $50 \pm 43$ \\
\hline Chao1 & $56 \pm 25$ & $49 \pm 26$ & $29 \pm 18$ & $30 \pm 23$ \\
\hline
\end{tabular}

species having representatives in Doñana's aquifer was that of the Acidobacteria. The Acidobacteria is a diverse taxon that, so far, has been predominantly detected in soils (Quaiser et al. 2003). In fact, the 2 different phylotypes identified in the sample 49S1 were most closely related to soil and rhizosphere clones (Fig. 4 and Appendix1).

In addition to phylotypes ascribed to known phyla, several Doñana sequences clustered with candidate bacterial divisions, and a few divergent ones did not affiliate with any described taxa. This was the case of phylotypes Doñana 49S1-2B-10, closely related to a rhizosphere environmental sequence and potentially related to the Chloroflexi, and Doñana 49S1-1B-52, forming a cluster with sequences from deep-sea sediment and crustal fluid (Fig. 4). The fact that these sequences clustered with other environmental sequences suggests that they do correspond to actual groups of organisms that await description. Some phylotypes were ascribed to the Candidate Division OP3, originally identified in a Yellowstone hot spring (Hugenholtz et al. 1998), and SPAM, which was identified in alpine soil (Lipson \& Schmidt 2004). The sequence Doñana 49S1-2B-60 nested within the Candidate Division Termite Group 1, also known as candidate phylum 'Endomicrobia', which are typical endosymbionts of strict anaerobic flagellate protists living in termite guts (Stingl et al. 2005). Endosymbiotic 'Endomicrobia' are thought to ferment and deliver hydrogen to the hydrogenosomes of anaerobic flagellates. Nevertheless, 'Endomicrobia' phylotypes are not exclusive to termite guts, since several environmental sequences retrieved from suboxic or anoxic environments belong to this group as well (Fig. 4). In fact, the closest relative to Doñana $49 \mathrm{~S} 1-2 \mathrm{~B}-60$ is a sequence from an Australian aquifer (Kimura et al. 2005).

OP11 and a novel division-level group identified recently in symbiotic consortia (Raghoebarsing et al. 2006) were the 2 candidate divisions relatively more abundant in Doñana 49S1 libraries. Phylotypes belonging to the OP11 were broadly distributed within this group (Fig. 4). Candidate Division OP11 was initially identified in a Yellowstone hot spring (Obsidian Pool) together with other OP lineages (Hugenholtz et al. 1998). Later, environmental sequences belonging to this large and highly diverse cluster were found in many different environments that had common properties of being anoxic, reduced and with a high concentration of sulphur species (Harris et al. 2004). In particular, OP11 appears to be abundant and diverse in deep 


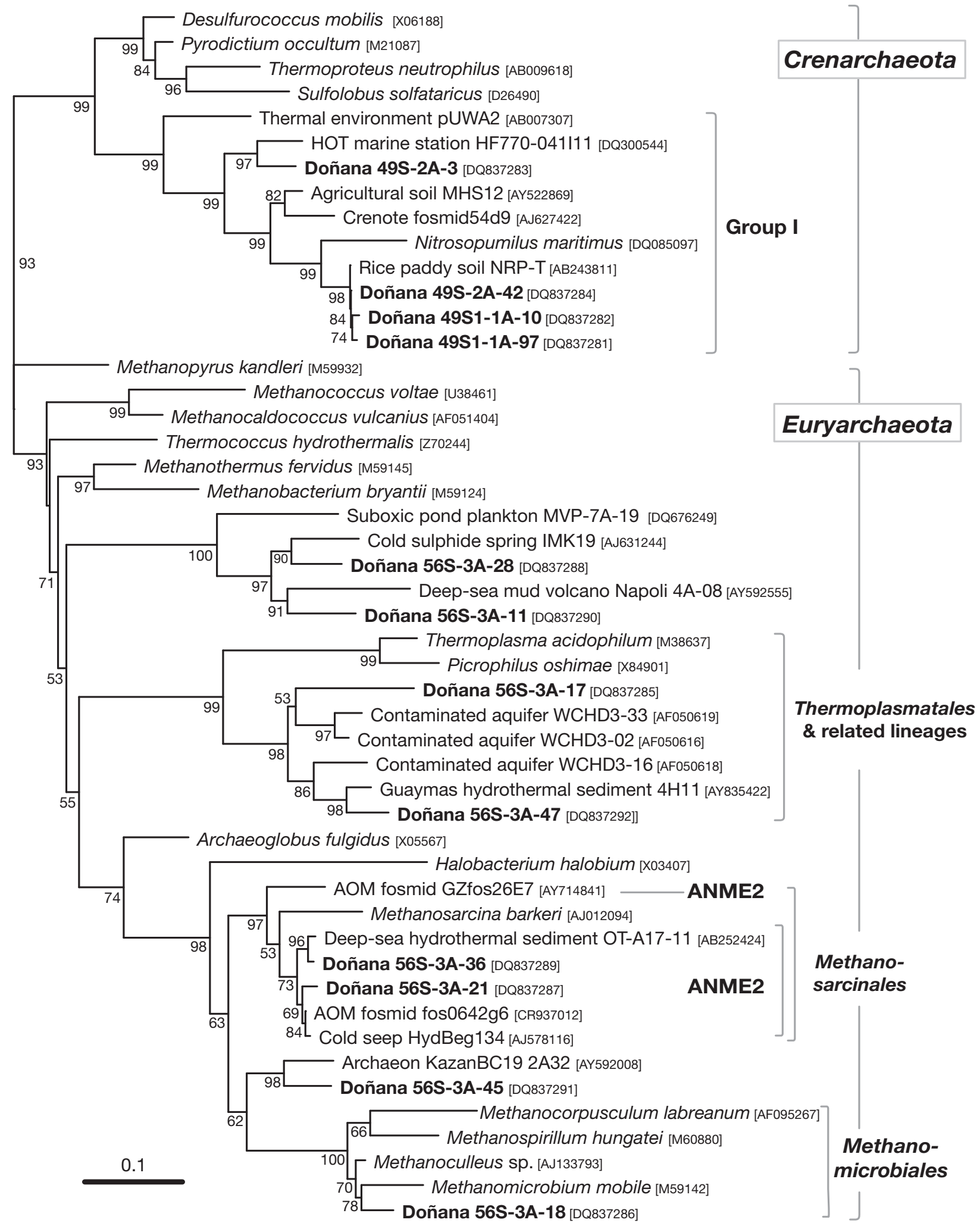

Fig. 3. Maximum likelihood phylogenetic tree showing the position of archaeal 16S rRNA phylotypes retrieved from a coastal freshwater aquifer in Doñana National Park. Italic names correspond to cultivated species or strains, the rest correspond to amplified 16S rRNA gene sequences unless otherwise specified (fosmid). Names in bold correspond to clones obtained in this study. Accession numbers are given in brackets only for environmental clones or non-described species. Only bootstrap values higher than $50 \%$ are given at nodes. AOM: anaerobic oxidation of methane 
Fig. 4. Maximum likelihood phylogenetic tree showing the position of bacterial phylotypes retrieved from a coastal freshwater aquifer in Doñana National Park to the exclusion of proteobacterial clones. Italic names correspond to cultivated species or strains, the rest correspond to 16S rRNA environmental clones. Names in bold correspond to clones obtained in this study. Accession numbers are given in brackets only for environmental clones or non-described species. Only bootstrap values higher than $50 \%$ are given at nodes. TG-1: Termite Group 1; AOM: anaerobic oxidation of methane. *: novel division-level group proposed by Raghoebarsing et al. (2006) including the bacterial symbiont of a denitrifying AOM consortium

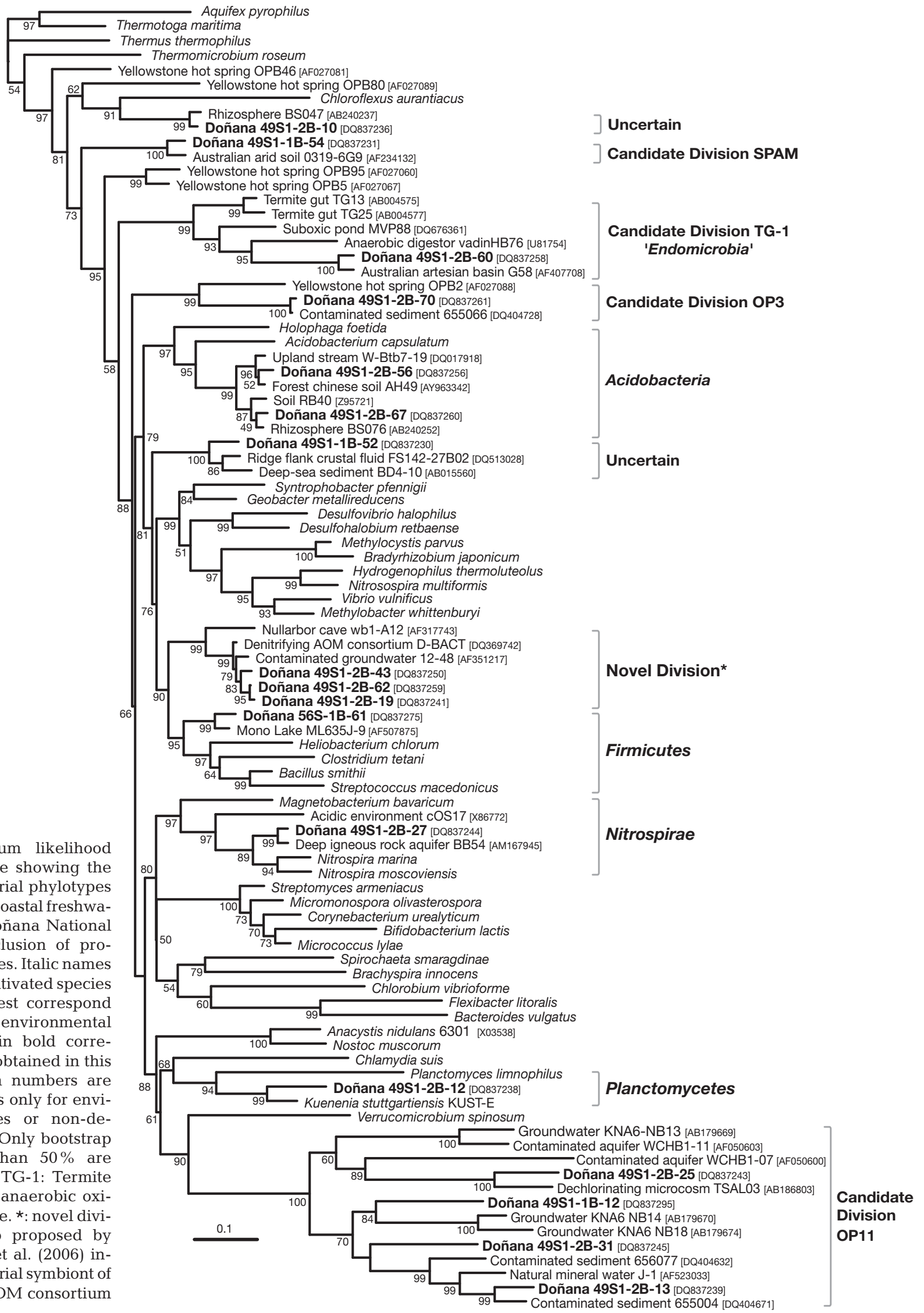

\section{Aquifex pyrophilus}

hermotoga maritima

thermophilus

ring OPB80 [AF027089] 2AB240237]

4

- Australian arid soil 0319-6G9 [AF234132]

wstone hot spring OPB5 [AF027067]

Termite gut TG13 [AB004575]

Anaerobic digestor vadinHB76 [U8175] Australian artesian basin G58

Candidate Division OP3 [00 Contaminated sediment 655066 [DQ404728

Holophaga foetida

oil AH49 [AY963342]

100

e flank crustal fluid FS142-27B02 [DQ513028]

alophilus

$100 \div$ Mradyrhizobium japonicum

99 - Nitrosospira multiformis

- Methylobacter whittenbury

a 56S-1B-61 [DQ837275]

(n) chlorum

97

- Bacillus smithi

oscoviensis

Planctomycetes

Division

OP11 
groundwater, being likely indigenous to subsurface biotopes (Dojka et al. 1998, Miyoshi et al. 2005). Although their metabolism is not yet known, given the type of environments where members of this group are found, it might be related to redox reactions involving sulphur compounds (Harris et al. 2004). Finally, a relatively high proportion of Doñana bacterial phylotypes was very closely related to the groundwater environmental sequence 12-48 and to the clone D-BACT (Fig. 4 andAppendix 1). The latter corresponds to the bacterial symbiont of an archaeal-bacterial consortium mediating the anaerobic oxidation of methane (AOM) coupled to nitrate reduction (Raghoebarsing et al. 2006). Until very recently, only AOM consortia coupling methane oxidation to sulphate reduction had been described (Boetius et al. 2000, Orphan et al. 2001a). These involve syntrophy between ANME1and ANME2-related Euryarchaeota and sulphatereducing Deltaproteobacteria. However, Raghoebarsing et al. (2006) succeeded in enriching AOM consortia from anoxic sediments in which putative methanotrophic archaea establish a syntrophic relationship with divergent denitrifying bacteria that form a novel division-level group. Since our Doñana sequences are very closely related to these bacteria, it could be hypothesised that they are denitrifiers that, perhaps, intervene in the AOM reactions. However, the latter point remains speculative, since we failed to amplify euryarchaeotal sequences from the 49S1 sample and, although the archaeal lineages detected by Raghoebarsing et al. (2006) in their AOM consortia do not affiliate with classical ANME groups, they are related to Euryarchaeota from contaminated soils and ferromanganese nodules in freshwater sediments (Raghoebarsing et al. 2006). We cannot exclude that Euryarchaeota are indeed present in this part of the aquifer, since, given the phylogenetic divergence within archaea, there are no truly archaeal-specific primers able to retrieve all archaeal lineages. Nevertheless, it might also be possible that these novel division bacteria are denitrifiers that can or cannot establish symbiotic consortia to carry out AOM.

\section{Proteobacteria}

As mentioned before, both the 49S1 and 56S libraries were dominated by phylotypes ascribed to the Betaproteobacteria and, to a lesser extent, the Gammaproteobacteria (Fig. 1). Phylotypes belonging to other proteobacterial subdivisions were much less abundant. Thus, deltaproteobacterial phylotypes were found only in the 49S1 sample. They formed a compact, but quite diverse, group related to sulphate-reducing species of the order Desulfovibrionales and 1 phylotype from
Yellowstone's Obsidian Pool (Fig. 5A). We indeed detected sulphate-reduction activity in the 49S1 aquifer using the BART system (see 'Materials and methods'), indicating that sulphate reduction is at least a potential activity in situ. Nevertheless, this method reported a higher sulphate-reducing activity in the 56S samples, despite the fact that we did not retrieve any Deltaproteobacteria or other typical sulphate-reducers in the corresponding 16S rRNA gene library. This suggested that sulphate reduction in the 56S aquifer sample was carried out by deltaproteobacterial species that were not recognised by our primers or by organisms not belonging to this phylogenetic group. At any rate, activities measured in the BARTs only indicate that those activities may occur in situ, as the experimental conditions are different in the laboratory test tubes.

The other proteobacterial subdivision found, Alphaproteobacteria, was mostly retrieved in 49S1. The only alphaproteobacterial phylotype found 56S was very closely related to a methyl-halide oxidising bacterium belonging to the Rhodobacteraceae, which are common aquifer inhabitants (Ball \& Crawford 2006; our Fig. 5A). Methyl halides are often associated with human pollution, but they can also be present in pristine environments, as they are naturally produced, e.g. by certain fungi, plants and marsh communities and during biomass decay (Rhew et al. 2003). Some 49S1 alphaproteobacterial phylotypes were closely related to clean- or contaminated-soil isolates, others to aquatic systems, including upland streams and wastewater-treatment reactors. Doñana 49S1-2B-2 had no close relatives, being only distantly related to Rhodobacter spp. Rhodobacter-related phylotypes have been identified in artesian pristine waters (Ball \& Crawford 2006). By contrast, 49S1-1B-36 was almost identical to several Methylocystis spp., including $M$. parvus. These species are aerobic methane-oxidisers, but they can also oxidise a wide range of aliphatic and aromatic compounds (Hanson \& Hanson 1996). Methanotrophic bacteria can also function at very low oxygen concentrations (Roslev \& King 1994), similar to those encountered in Doñana's aquifer samples. As other gammaproteobacterial methanotroph-like sequences have also been found (see below), it could be hypothesised that aerobic methane oxidation might exist in this aquifer under microaerophilic conditions.

Our phylotypes were widely distributed in the betaproteobacterial tree, although there was little overlap between the subgroups found in the 2 aquifers (Fig. 5B). A number of 56S phylotypes (Doñana 56S1B-48, 56S-1B-81, 56S-1B-20 and 56S-1B-30) emerged within well-supported groups with other clones retrieved in sulphide-rich environments (caves and mines). These lineages are distantly related to the 


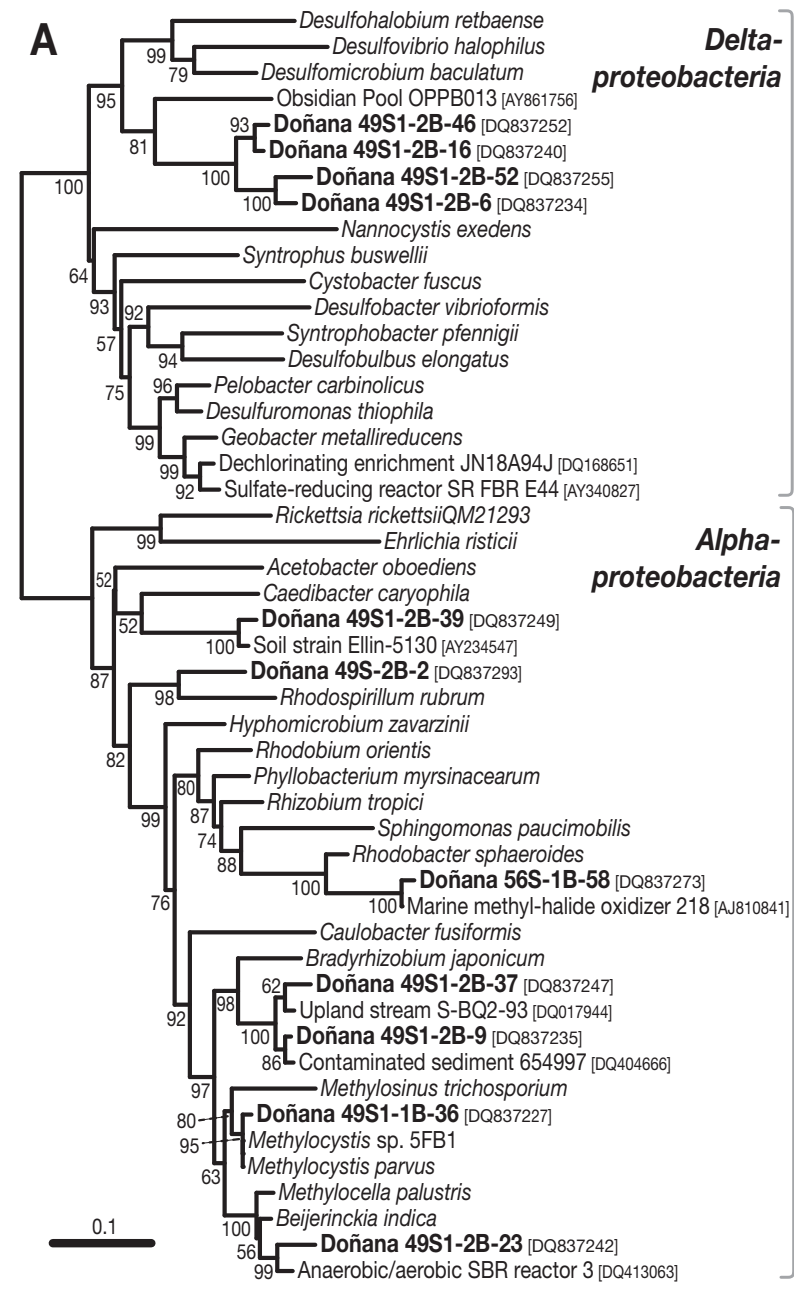

Fig. 5. Maximum likelihood phylogenetic trees showing the position of Proteobacteria phylotypes retrieved from a coastal freshwater aquifer in Doñana National Park. (A) Deltaproteobacteria and Alphaproteobacteria; (B) Beta- and Gammaproteobacteria. Italic names correspond to cultivated species or strains, the rest correspond to $16 \mathrm{~S}$ rRNA environmental clones. Names in bold correspond to clones obtained in this study. Accession numbers are given in brackets only for environmental clones or non-described species. Only bootstrap values higher than $50 \%$ are given at nodes

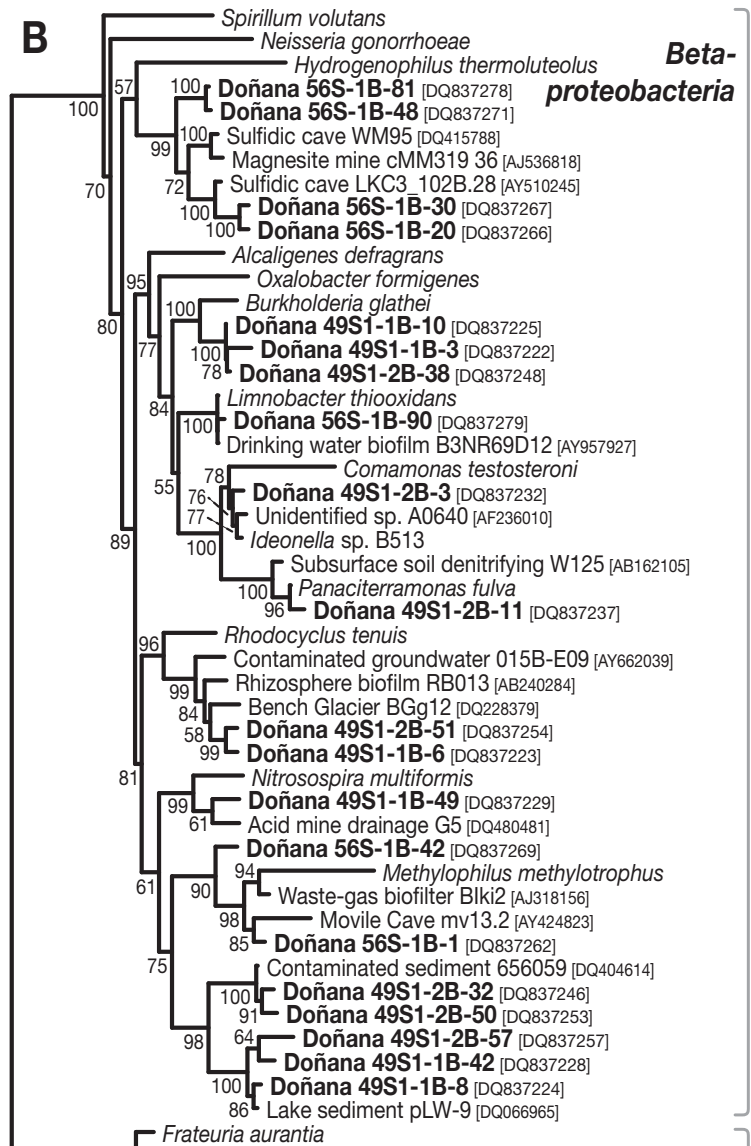

Frateuria aurantia

${ }_{94}^{100}$ - Doñana 49S1-18

${ }_{92}-$ Frateuria sp NO-16

Methylococcus capsulatus

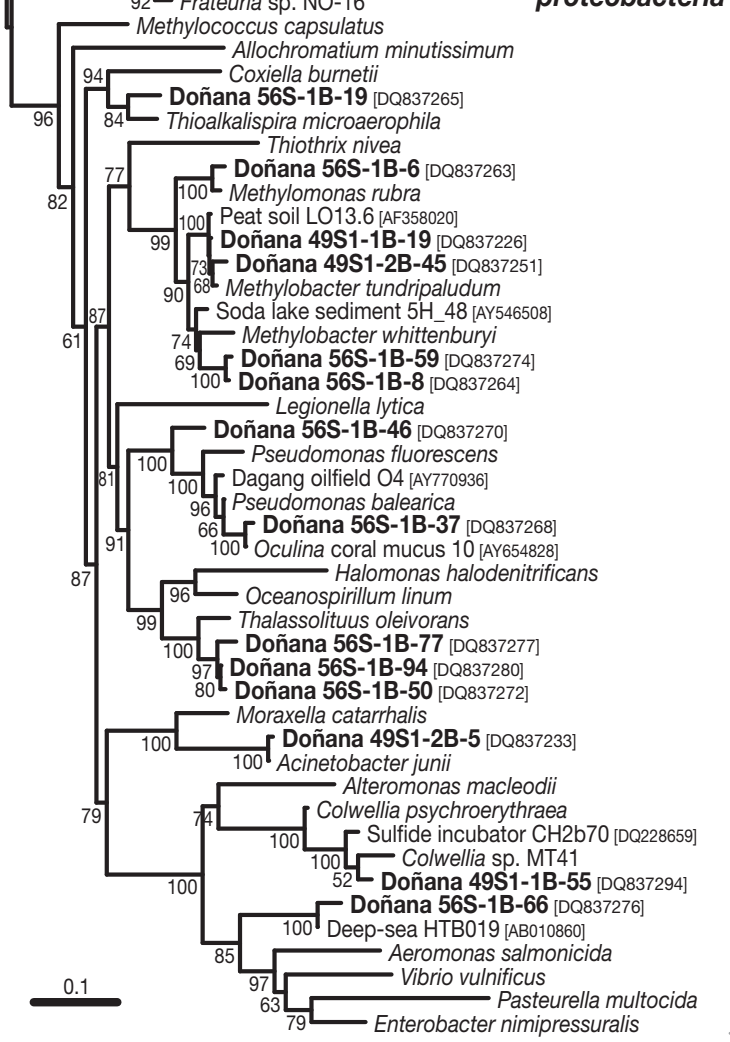


sulphur-oxidising genus Thiobacter, within the order Hydrogenophilales. That was also the case for Doñana 56S-1B-90, which was almost identical to the chemolithoheterotroph Limnobacter thiooxidans. Most of the 49S1 phylotypes branched within groups containing mostly heterotrophic species, such as those related to the genera Burkholderia and Rhodocyclus or to the Comamonas-Variovorax clade. Betaproteobacteria belonging to these groups have been frequently detected in 16S rRNA surveys of aquifers (Pedersen et al. 1996, Ball \& Crawford 2006). The phylotype Doñana 49S1-1B-49 was related to Nitrosospira, a genus of ammonium-oxidising bacteria that appears very abundant in anoxic marine sediments (Freitag \& Prosser 2003) and dominates in nitrifying bed reactors (Schramm et al. 1998). Notably, a large proportion of the clones in the $56 \mathrm{~S}$ library (26 clones nearly identical to Doñana 56S-1B-1 in Fig. 5B) were related to the betaproteobacterial genus Methylophilus, together with 1 phylotype slightly more distantly related. Methylophilus spp. metabolise a variety of $\mathrm{C}_{1}$ compounds other than methane (e.g. methanol, methylamines), which are present in lake sediments (Nercessian et al. 2005).

We observed similar trends for the gammaproteobacterial phylotypes, since Doñana sequences were also broadly scattered within this group and since clones from the 2 depth samples were not generally mixed. The only exception was that of gammaproteobacterial methanotrophs, including members of the genera Methylomonas and Methylobacter (Fig. 5B). Both 49S1 and 56S sequences were found to affiliate with this cluster, suggesting that aerobic methanotrophy might occur at both aquifer depths. In addition to methanotrophic-like sequences, most of the remaining gammaproteobacterial phylotypes were closely related to typically heterotrophic genera such as Frateuria, Pseudomonas, Thalassolituus, Acinetobacter, and Colwellia. Doñana 56S-1B-19 was closely related to Thioalkalispira microaerophila, a versatile lithoautotrophic oxidiser of sulphur species (Sorokin et al. 2002).

As mentioned above, betaproteobacterial phylotypes were by far the most diverse and abundant in 49S1 libraries. They were also very diverse and abundant in 56S libraries but, in this case, they were nearly equalled by the Gammaproteobacteria (Figs. 1 \& 5). Betaproteobacteria are abundant in freshwater, including groundwater (e.g. Lindstrom et al. 2005, Miyoshi et al. 2005, Van der Gucht et al. 2005), and therefore it is not surprising to find them associated with the Doñana aquifer. Gammaproteobacteria are also widespread in many environments, but are particularly diverse and abundant in seawater (Venter et al. 2004, DeLong et al. 2006). This, together with the fact that the $56 \mathrm{~S}$ sample has a conductivity value intermediate between those of fresh and seawater, suggests that this particular region of the aquifer receives some input of marine water and its associated microbiota. Indeed, some of the 56S gammaproteobacterial phylotypes are closely related to typical marine bacteria, such as Thalassolituus and Colwellia spp. (Fig. 5).

In summary, the Doñana aquifer phylotypes belonging to the highly versatile Proteobacteria tended to group with heterotrophic lineages, sulphate-reducers (exclusively in the shallower aquifer sample 49S1) and other S-metabolisers (Limnobacter, Thioalkalispira), ammonium-oxidising bacteria (Nitrosospira-like) and, most of all, with $\mathrm{C}_{1}$-metabolising microorganisms, including typical methanotrophs of the alpha(Methylocystis) and gammaproteobacterial (Methylobacter, Methylomonas) subdivisions as well as with methylotrophic species of the Betaproteobacteria (Methylophilus). This suggests that aerobic methane oxidation, under microaerophilic conditions, might be an important process in the 2 aquifer sub-systems.

\section{Concluding remarks}

Most environmental sequences retrieved from Doñana's aquifer were related to phylotypes identified in contaminated aquifers and other underground habitats. Since Doñana's aquifer is a pristine environment, this suggests that a portion of the sequences found in contaminated aquifers actually correspond to the indigenous microbiota associated with subsurface systems. In fact, contaminated aquifers are often polluted with hydrocarbon and chlorinated compounds, but these can also be naturally produced during the decomposition and detrital processing of organic matter (Sanderman \& Amundson 2005). We detected higher phenol oxidase activities in the deeper Doñana sample. Conversely, greater enzymatic activities related to the degradation of the labile pool of organic matter (nucleic acids, proteins and polysaccharides) were observed in the shallower sample. This would agree with the sequential degradation of organic matter as a function of depth, with easily degradable organic pools preferentially degraded in upper layers and complex organic matter fractions reaching deeper aquifer regions (Sanderman \& Amundson 2005).

Several of the Doñana's aquifer phylotypes were closely related to cultivated species of known metabolism, which, together with the biological activities assayed in the laboratory, allows the potential occurrence of some metabolic processes in this ecosystem to be hypothesised. Many phylotypes were related to typical heterotrophic bacteria, mostly within the Proteobacteria, in agreement with various hydrolytic enzy- 
matic activities measured in the laboratory (Table 1). Iron redox activities were measured in Doñana's aquifer samples (Table 1). Sulphate reduction was also detected in both aquifer samples in the laboratory (Table 1), although the precise identity of potential sulphate-reducers could not be established in the deeper sample. Sulphur-oxidising bacteria could be represented in our samples by a betaproteobacterial cluster within the Hydrogenophilales, Limnobacter- and Thioalkalispira-like phylotypes and, perhaps, the OP11 division (Harris et al. 2004). Nitrogen and methane cycles could also be active in Doñana's aquifer. Many phylotypes were related to species involved in nitrogen cycling. They correspond to lineages that might be responsible for the aerobic oxidation of ammonia to nitrite, such as those related to the classical nitrifier genus Nitrosospira within the Betaproteobacteria (Schramm et al. 1998) and, likely, the crenarchaeotal Group I phylotypes (Francis et al. 2005, Konneke et al. 2005, Nicol \& Schleper 2006). Members of the methanotrophic Proteobacteria, well represented in Doñana's aquifer, can also oxidise ammonia using methane monooxygenase (Hanson \& Hanson 1996). Phylotypes related to nitrite-oxidising lineages within the phylum Nitrospirae are also present. In addition, the presence of Doñana sequences related to the versatile anammox planctomycete Kuenenia stuttgartensis suggests a potential for the anaerobic oxidation of ammonium to $\mathrm{N}_{2}$ using nitrite (Strous et al. 1999).

In the opposite direction, denitrification was measured in Doñana samples (Table 1). This activity appears to be important in coastal aquifers where the presence of archaeal amo genes has been reported (Francis et al. 2005, Santoro et al. 2006). Potential nitrate-respiring candidates in Doñana might correspond to phylotypes related to the denitrifiers Thioalkalispira, Burkholderia, Limnobacter, the Comamonas group, or the novel denitrifying AOM-related division (Raghoebarsing et al. 2006). Finally, lineages involved in methane metabolism also occurred in Doñana's aquifer, particularly in the deepest sample. These included typical methanogenic archaea (Methanomicrobiales) and a variety of lineages related to aerobic methane oxidisers (Methylocystis, Methylobacter, Methylomonas) and anaerobic methane oxidisers (Methanosarcinales ANME2 group). This might indicate that aerobic and anaerobic methane oxidation could co-occur in certain regions of the aquifer. To date, anaerobic methane oxidation by ANME-related archaea has been reported nearly exclusively in marine sediments (Orphan et al. 2001b, Knittel et al. 2005), although a recent study showed that ANMErelated anaerobic methanotrophs coexist with bacterial aerobic methanotrophs in a freshwater lake (Eller et al. 2005). The co-occurrence of both methane oxidation processes might be more widespread in nature than previously thought, as this is also the case for subsurface ecosystems.

Acknowledgements. We are grateful to C. Guerrero for helpful discussions and advice. This work was supported by the Spanish Centro de Investigación Científica y Technólogica (CICYT) grant no. REN2002-10221-E/HID and an Action Thématique Incitative sur Programme (ATIP) Plus grant by the French Centre National de la Recherche Scientifique, section 'Dynamique de la biodiversité', to P.L.-G.

\section{LITERATURE CITED}

Altschul SF, Madden TL, Schaffer AA, Zhang J, Zhang Z, Miller W, Lipman DJ (1997) Gapped BLAST and PSIBLAST: a new generation of protein database search programs. Nucleic Acids Res 25:3389-3402

APHA, AWWA, WPCF (1989) Standard methods for the examination of water and wastewater. American Public Health Association, Washington, DC

Balkwill DL, Ghiorse WC (1985) Characterization of subsurface bacteria associated with two shallow aquifers in Oklahoma. Appl Environ Microbiol 50:580-588

Ball CL, Crawford RL (2006) Bacterial diversity within the planktonic community of an artesian water supply. Can J Microbiol 52:246-259

Bernard L, Courties C, Servais P, Troussellier M, Petit M, Lebaron P (2000) Relationships among bacterial cell size, productivity, and genetic diversity in aquatic environments using cell sorting and flow cytometry. Microb Ecol 40:148-158

Boetius A, Ravenschlag K, Schubert CJ, Rickert D and 6 others (2000) A marine microbial consortium apparently mediating anaerobic oxidation of methane. Nature 407: 623-626

Bölter M, Bloem J, Meiners K, Möller R (2002) Enumeration and biovolume determination of microbial cells-a methodological review and recommendations for applications in ecological research. Biol Fertil Soils 36:249-259

Chapelle FH, O'Neill K, Bradley PM, Methe BA, Ciufo SA, Knobel LL, Lovley DR (2002) A hydrogen-based subsurface microbial community dominated by methanogens. Nature 415:312-315

Cullimore R (1993) Practical manual of groundwater microbiology. Lewis Publishers, Chelsea, MI

Custodio E, Manzano M, Iglesias M, Giraldez JV (1995) Hidrología del Abalario. Parque Natural del Entorno de Doñana. Consejería de Medio Ambiente, Junta de Andalucía

Daims H, Nielsen JL, Nielsen PH, Schleifer KH, Wagner M (2001) In situ characterization of Nitrospira-like nitriteoxidizing bacteria active in wastewater treatment plants. Appl Environ Microbiol 67:5273-5284

DeLong EF, Preston CM, Mincer T, Rich V and 8 others (2006) Community genomics among stratified microbial assemblages in the ocean's interior. Science 311:496-503

Detmers J, Schulte U, Strauss H, Kuever J (2001) Sulfate reduction at a lignite seam: microbial abundance and activity. Microb Ecol 42:238-247

Dojka MA, Hugenholtz P, Haack SK, Pace NR (1998) Microbial diversity in a hydrocarbon- and chlorinated-solventcontaminated aquifer undergoing intrinsic bioremediation. Appl Environ Microbiol 64:3869-3877 
Edwards KJ, Bach W, McCollom TM (2005) Geomicrobiology in oceanography: microbe-mineral interactions at and below the seafloor. Trends Microbiol 13:449-456

Eller G, Kanel L, Kruger M (2005) Cooccurrence of aerobic and anaerobic methane oxidation in the water column of Lake Plusssee. Appl Environ Microbiol 71:8925-8928

Fahy A, Lethbridge G, Earle R, Ball AS, Timmis KN, McGenity TJ (2005) Effects of long-term benzene pollution on bacterial diversity and community structure in groundwater. Environ Microbiol 7:1192-1199

Farnleitner AH, Wilhartitz I, Ryzinska G, Kirschner AK and 6 others (2005) Bacterial dynamics in spring water of alpine karst aquifers indicates the presence of stable autochthonous microbial endokarst communities. Environ Microbiol 7:1248-1259

Fisk MR, Giovannoni SJ, Thorseth IH (1998) Alteration of oceanic volcanic glass: textural evidence of microbial activity. Science 281:978-980

Francis CA, Roberts KJ, Beman JM, Santoro AE, Oakley BB (2005) Ubiquity and diversity of ammonia-oxidizing archaea in water columns and sediments of the ocean. Proc Natl Acad Sci USA 102:14683-14688

Freitag TE, Prosser JI (2003) Community structure of ammonia-oxidizing bacteria within anoxic marine sediments. Appl Environ Microbiol 69:1359-1371

Fry JC (1990) Direct methods and biomass estimation. Methods Microbiol 22:43-85

Fry NK, Fredrickson JK, Fishbain S, Wagner M, Stahl DA (1997) Population structure of microbial communities associated with two deep, anaerobic, alkaline aquifers. Appl Environ Microbiol 63:1498-1504

Ghiorse WC, Wilson JT (1988) Microbial ecology of the terrestrial subsurface. Adv Appl Microbiol 33:107-172

Griebler C, Mindl B, Slezak D, Geiger-Kaiser M (2002) Distribution patterns of attached and suspended bacteria in pristine and contaminated shallow aquifers studied with an in situ sediment exposure microcosm. Aquat Microb Ecol 28:117-129

Hallam SJ, Putnam N, Preston CM, Detter JC, Rokhsar D, Richardson PM, DeLong EF (2004) Reverse methanogenesis: testing the hypothesis with environmental genomics. Science 305:1457-1462

Hanson RS, Hanson TE (1996) Methanotrophic bacteria. Microbiol Rev 60:439-471

Harris JK, Kelley ST, Pace NR (2004) New perspective on uncultured bacterial phylogenetic division OP11. Appl Environ Microbiol 70:845-849

Haveman SA, Pedersen K (2002) Distribution of culturable anaerobic microorganisms in Fennoscandian shield ground water. FEMS Microbiol Ecol 39:129-137

Hirsch P, Rades-Rohkohl E (1990) Microbial colonization of aquifer sediment exposed in a groundwater well in northern Germany. Appl Environ Microbiol 56:2963-2966

Hugenholtz P, Pitulle C, Hershberger KL, Pace NR (1998) Novel division level bacterial diversity in a Yellowstone hot spring. J Bacteriol 180:366-376

Iglesias M (1999) Caracterizacion hidrogeoquimica del flujo de agua subterranea en el Abalario, Doñana, Huelva. $\mathrm{PhD}$ dissertation, Universidad Politecnica de Cataluña, Barcelona

Karl DM (1980) Cellular nucleotide measurements and applications in microbial ecology. Microbiol Rev 44: 739-796

Kimura H, Sugihara M, Yamamoto H, Patel BK, Kato K, Hanada S (2005) Microbial community in a geothermal aquifer associated with the subsurface of the Great Artesian Basin, Australia. Extremophiles 9:407-414
Kirchman DL, K'nees E, Hodson RE (1985) Leucine incorporation and its potential as a measure of protein synthesis by bacteria in natural aquatic systems. Appl Environ Microbiol 49:599-607

Kleikemper J, Schroth MH, Sigler WV, Schmucki M, Bernasconi SM, Zeyer J (2002) Activity and diversity of sulfate-reducing bacteria in a petroleum hydrocarboncontaminated aquifer. Appl Environ Microbiol 68: 1516-1523

Knittel K, Losekann T, Boetius A, Kort R, Amann R (2005) Diversity and distribution of methanotrophic archaea at cold seeps. Appl Environ Microbiol 71:467-479

Konneke M, Bernhard AE, de la Torre JR, Walker CB, Waterbury JB, Stahl DA (2005) Isolation of an autotrophic ammonia-oxidizing marine archaeon. Nature 437: 543-546

Leclerc H, Moreau A (2002) Microbiological safety of natural mineral water. FEMS Microbiol Rev 26:207-222

Lehman RM, Roberto FF, Earley D, Bruhn DF, Brink SE, O'Connell SP, Delwiche ME, Colwell FS (2001) Attached and unattached bacterial communities in a 120-meter corehole in an acidic, crystalline rock aquifer. Appl Environ Microbiol 67:2095-2106

Lindstrom ES, Kamst-Van Agterveld MP, Zwart G (2005) Distribution of typical freshwater bacterial groups is associated with $\mathrm{pH}$, temperature, and lake water retention time. Appl Environ Microbiol 71:8201-8206

Lipson DA, Schmidt SK (2004) Seasonal changes in an alpine soil bacterial community in the Colorado Rocky Mountains. Appl Environ Microbiol 70:2867-2879

López-Archilla A, Moreira D, López-García P, Guerrero C (2004) Phytoplankton diversity and cyanobacterial dominance in a hypereutrophic shallow lake with biologicallyproduced alkaline $\mathrm{pH}$. Extremophiles 8:109-115

Lozano E (2004) Las aguas subterraneas en los cotos de Doñana y su influencia en las lagunas. PhD dissertation, Universidad Politecnica de Cataluña, Barcelona

Lozano E, Palancar N (1995) Las aguas subterraneas en Doñana. Rev Obras Publicas 3340:31-53

Miyoshi T, Iwatsuki T, Naganuma T (2005) Phylogenetic characterization of $16 \mathrm{~S}$ rRNA gene clones from deepgroundwater microorganisms that pass through 0.2micrometer-pore-size filters. Appl Environ Microbiol 71: $1084-1088$

Nercessian O, Noyes E, Kalyuzhnaya MG, Lidstrom ME, Chistoserdova L (2005) Bacterial populations active in metabolism of $\mathrm{C} 1$ compounds in the sediment of Lake Washington, a freshwater lake. Appl Environ Microbiol 71:6885-6899

Nicol GW, Schleper C (2006) Ammonia-oxidising Crenarchaeota: important players in the nitrogen cycle? Trends Microbiol 14:207-212

Orphan VJ, Hinrichs KU, Ussler W III, Paull CK, Taylor LT, Sylva SP, Hayes JM, Delong EF (2001a) Comparative analysis of methane-oxidizing archaea and sulfate-reducing bacteria in anoxic marine sediments. Appl Environ Microbiol 67:1922-1934

Orphan VJ, House CH, Hinrichs KU, McKeegan KD, DeLong EF (2001b) Methane-consuming archaea revealed by directly coupled isotopic and phylogenetic analysis. Science 293:484-487

Page RD (1996) TreeView: an application to display phylogenetic trees on personal computers. Comput Appl Biosci 12:357-358

Parkes RJ, Webster G, Cragg BA, Weightman AJ and 6 others (2005) Deep sub-seafloor prokaryotes stimulated at interfaces over geological time. Nature 436:390-394 
Pedersen K (2000) Exploration of deep intraterrestrial microbial life: current perspectives. FEMS Microbiol Lett 185: 9-16

Pedersen K (2001) Diversity and activity of microorganisms in deep igneous rock aquifers of the Fennoscandian shield. In: Fredrickson $\mathrm{K}$, Fletcher $\mathrm{M}$ (eds) Subsurface microgeobiology and biogeochemistry. Wiley-Liss, New York, p 97-139

Pedersen K, Arlinger J, Hallbeck L, Pettersson C (1996) Diversity and distribution of subterranean bacteria in groundwater at Oklo in Gabon, Africa, as determined by $16 \mathrm{~S}$ rRNA gene sequencing. Mol Ecol 5:427-436

Philippe H (1993) MUST, a computer package of Management Utilities for Sequences and Trees. Nucleic Acids Res 21:5264-5272

Quaiser A, Ochsenreiter T, Lanz C, Schuster SC, Treusch AH, Eck J, Schleper C (2003) Acidobacteria form a coherent but highly diverse group within the bacterial domain: evidence from environmental genomics. Mol Microbiol 50:563-575

Raghoebarsing AA, Pol A, van de Pas-Schoonen KT, Smolders AJ and 7 others (2006) A microbial consortium couples anaerobic methane oxidation to denitrification. Nature 440:918-921

Rhew RC, Ostergaard L, Saltzman ES, Yanofsky MF (2003) Genetic control of methyl halide production in Arabidopsis. Curr Biol 13:1809-1813

Roslev P, King GM (1994) Survival and recovery of methanotrophic bacteria starved under oxic and anoxic conditions. Appl Environ Microbiol 60:2602-2608

Sanderman J, Amundson R (2005) Biogeochemistry of decomposition and detrital processing. In: Holland HD, Turekian KK (eds) Treatise on geochemistry. Biogeochemistry, Vol 8. Elsevier, Oxford, p 249-316

Santoro AE, Boehm AB, Francis CA (2006) Denitrifier community composition along a nitrate and salinity gradient in a coastal aquifer. Appl Environ Microbiol 72:2102-2109

Schippers A, Neretin LN, Kallmeyer J, Ferdelman TG, Cragg BA, Parkes RJ, Jorgensen BB (2005) Prokaryotic cells of the deep sub-seafloor biosphere identified as living bacteria. Nature 433:861-864

Schleper C, Jurgens G, Jonuscheit M (2005) Genomic studies of uncultivated archaea. Nat Rev Microbiol 3:479-488

Schloss PD, Handelsman J (2005) Introducing DOTUR, a computer program for defining operational taxonomic units and estimating species richness. Appl Environ Microbiol 71:1501-1506

Schramm A, De Beer D, Wagner M, Amann R (1998) Identification and activities in situ of Nitrosospira and Nitrospira spp. as dominant populations in a nitrifying fluidized bed reactor. Appl Environ Microbiol 64:3480-3485

Shi Y, Zwolinski MD, Schreiber ME, Bahr JM, Sewell GW, Hickey WJ (1999) Molecular analysis of microbial community structures in pristine and contaminated aquifers: field and laboratory microcosm experiments. Appl Environ Microbiol 65:2143-2150

Editorial responsibility: Ruben Sommaruga, Innsbruck, Austria
Simon M, Azam F (1989) Protein content and protein synthesis rates of planktonic marine bacteria. Mar Ecol Prog Ser 51:201-213

Singleton DR, Furlong MA, Rathbun SL, Whitman WB (2001) Quantitative comparisons of 16S rRNA gene sequence libraries from environmental samples. Appl Environ Microbiol 67:4374-4376

Sinsabaugh RL, Osgood MP, Findlay S (1994) Enzymatic models for estimating decomposition rates of particulate detritus. J North Am Benthol Soc 13:160-169

Sorokin DY, Tourova TP, Kolganova TV, Sjollema KA, Kuenen JG (2002) Thioalkalispira microaerophila gen. nov., sp. nov., a novel lithoautotrophic, sulfur-oxidizing bacterium from a soda lake. Int J Syst Evol Microbiol 52:2175-2182

Stingl U, Radek R, Yang H, Brune A (2005) 'Endomicrobia': cytoplasmic symbionts of termite gut protozoa form a separate phylum of prokaryotes. Appl Environ Microbiol 71: 1473-1479

Strous M, Fuerst JA, Kramer EH, Logemann S and 5 others (1999) Missing lithotroph identified as new planctomycete. Nature 400:446-449

Strous M, Pelletier E, Mangenot S, Rattei T and 33 others (2006) Deciphering the evolution and metabolism of an anammox bacterium from a community genome. Nature 440:790-794

Takai K, Moser DP, DeFlaun M, Onstott TC, Fredrickson JK (2001) Archaeal diversity in waters from deep South African gold mines. Appl Environ Microbiol 67: 5750-5760

Thompson JD, Gibson TJ, Plewniak F, Jeanmougin F, Higgins DG (1997) The ClustalX windows interface: flexible strategies for multiple sequence alignment aided by quality analysis tools. Nucleic Acids Res 24:4876-4882

Treusch AH, Leininger S, Kletzin A, Schuster SC, Klenk HP, Schleper C (2005) Novel genes for nitrite reductase and Amo-related proteins indicate a role of uncultivated mesophilic crenarchaeota in nitrogen cycling. Environ Microbiol 7:1985-1995

Trick T, Custodio E (2004) Hydrodynamic characteristics of the western Doñana Region (area of El Abalario), Huelva, Spain. Hydrogeol J 12:321-335

Van der Gucht K, Vandekerckhove T, Vloemans N, Cousin $S$ and 6 others (2005) Characterization of bacterial communities in four freshwater lakes differing in nutrient load and food web structure. FEMS Microbiol Ecol 53: 205-220

Venter JC, Remington K, Heidelberg JF, Halpern AL and 19 others (2004) Environmental genome shotgun sequencing of the Sargasso Sea. Science 304:66-74

Viollier E, Iinglett PW, Hunter K, Roychoudhury AN, Van Cappellen P (2000) The ferrozine method revisited: $\mathrm{Fe}(\mathrm{II}) / \mathrm{Fe}(\mathrm{III})$ determination in natural waters. Appl Geochem 15:785-790

Wuchter C, Schouten S, Boschker HT, Sinninghe Damste JS (2003) Bicarbonate uptake by marine Crenarchaeota. FEMS Microbiol Lett 219:203-207

Submitted: October 6, 2006; Accepted: February 27, 2007

Proofs received from author(s): March 30, 2007 